\title{
ASD in school: from theory and research to educational practice
}

\section{Claudia - Vasilica BORCA•}

\begin{abstract}
As a result of increase of the Autism Spectrum Disorder (ASD) prevalence, teachers are experiencing real difficulties such as, the curriculum, social, emotional, and behavioural development of these students. The main purpose of this paper is to analyse how the effectiveness and quality of educational and therapeutic practice in ASD are influenced by research in the field, by identifying those interventions and effective, scientifically validated treatments for students with ASD. Initially, we will present the current conceptualization of ASD, the review of scientific literature, analysis of research studies, identification and analysis of practices. We want to find out what is the link between educational practices and studies that provide empirical support for those practices. A range of effective scientifically validated interventions and treatments for children with ASD, evidence-based practices (EBPS), school-based instructional interventions research, research-based principles and practices are presented.
\end{abstract}

Keywords: Autism Spectrum Disorder (ASD); educational practices; research; evidence.

\section{Introduction}

The of Autism Spectrum Disorder (ASD) belongs to category of neurodevelopmental disorder, characterized by "persistent impairment in reciprocal social communication and social interaction (challenges in social reciprocity, nonverbal social behaviours, and establishment of social relationships), and restricted, repetitive patterns of behaviour, interests, or activities (stereotypic behaviour or speech, excessive adherence to routines, and highly fixated interests)from early childhood and limit or impair everyday functioning" (Diagnostic and Statistical Manual of Mental Disorders (DSM), 2013; C. Wong\& al, 2014). Besides these particularities, in the DSM-5 (2013), "co-occurring conditions, such as intellectual disability or attention deficit hyperactive disorder, may also be diagnosed when a diagnosis of ASD is made."

\footnotetext{
- PhD. Lecturer, West University of Timisoara, University Clinic for Therapies and Psycho-pedagogic Counselling claudia.borca@e-uvt.ro
} 
For this reason, the school integration of children with ASD is probably the greatest challenge for educational systems over seven decades. It has been tried to find a solution that responds to the needs of educational partners: school, family, child itself, but also community. According with Tutunaru (2018), "integrated education is a component of the development of a community that aims to attract the participation of and to actively involve, through combined efforts, schools, families of children with special education needs, and members of their community." In this perspective, "in order to participate as part of the school community, students with Autism need to develop appropriate social behaviours." (Little, 2017, p. 34)

Besides that, according with DSM-5 (2013),"in recent years, reported frequencies for autism spectrum disorder across U.S. and non- U.S. countries have approached $1 \%$ of the population, with similar estimates in child and adult samples." As a result of this high increase of ASD prevalence, teachers face real difficulties in implementing curricula and promotingsocial, emotional and behavioural development of this children because of the student's social deficits. (Cavanaugh, C. M., 2012; Boutot, Eman\& Farrell, 2010; Parson's \& Lewis, 2009)"The prevalence of ASD has increased over the past two decades, rising from 2 per 10,000 in 1990 to between 1 in 50 and 1 in 88 children" (Blumberg, et al., 2013; Centres for Disease Control and Prevention, 2012) (C. Wong \& al, 2014). Current estimates that 1 in 68 children are diagnosed with Autism Spectrum Disorder (ASDs) (according to Centres for Disease Control and Prevention, 2015)

For this reason, the subject of school inclusion of students with ASD has been developed theoretically, researched and then implemented in evidence-based educational practices, enhancing the efficiency of educational and therapeutic services.

Educational and therapeutic intervention in ASD has overcome the stage of unidirectional, patterned, no contextualized interventional practices, and it is currently discussed the intervention science applied in comprehensive treatment models. (C. Wong\& al, 2014) 


\section{Comprehensive Treatment Models (CTMs)}

CTMs involve a set of "practices organised around a conceptual framework"and they are defined as "a set of practices designed to achieve a broad learning or developmental impact on the core deficits of ASD" (National Research Council, 2001, http://www.researchautism.net/glossary/1528/comprehensive-treatment models)

CTMs have a long history as sources for intervention, therapeutic, and educational services. (Odom, Boyd, Hall, Hume, 2014)

In the last decades, there have been many concerns to find practices leading to the expected results of ASD learning, which have materialized in comprehensive treatment models (CTMs).

"The National Academy of Educational Interventions for Children with Autism, through education programs for children with ASD, identified 10 CTMs."(National Research Council, 2001)

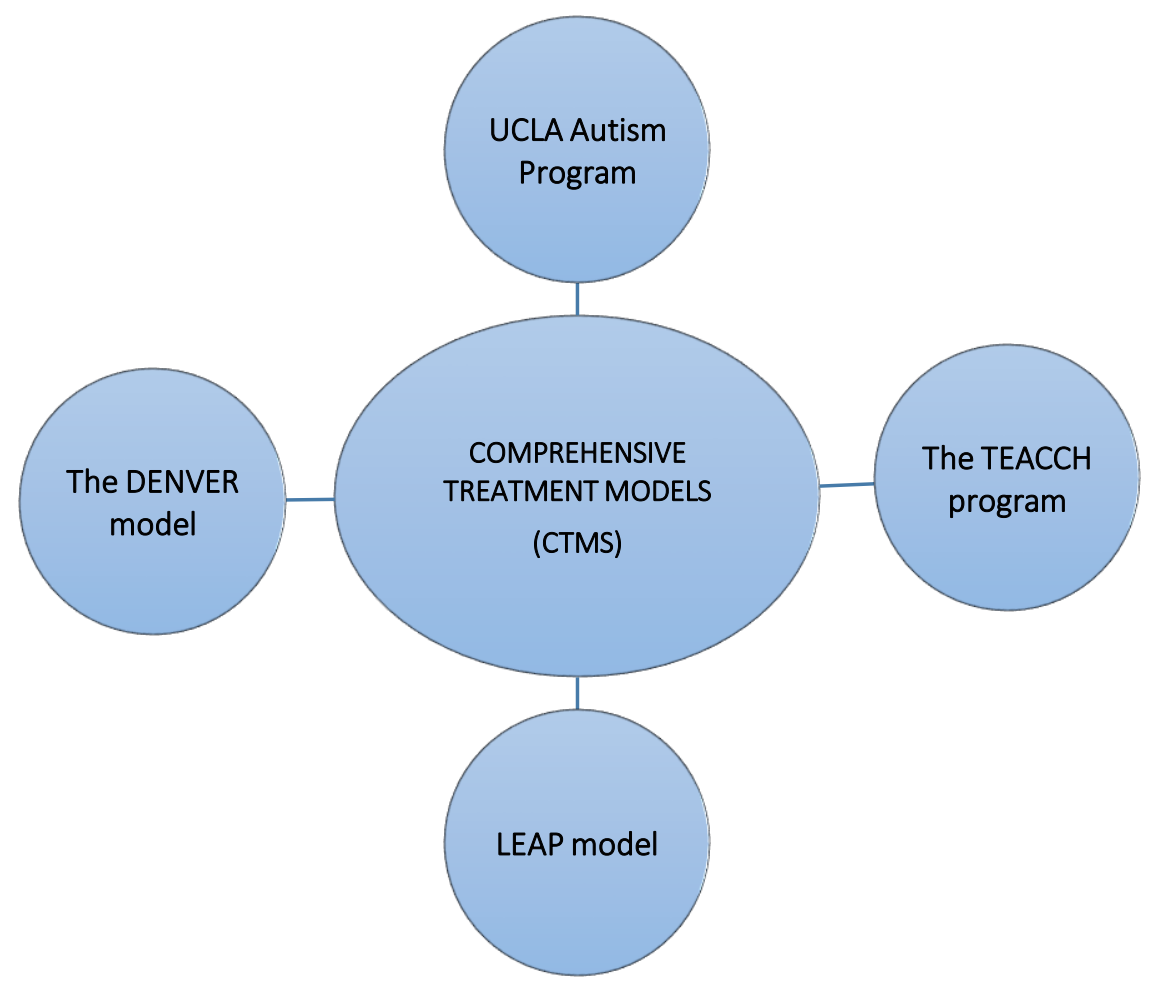

Figure 1. Comprehensive Treatment Models (CTMs), The National Academy of Educational Interventions for Children with Autism (National Research Council, 2001) 
The Figure 1 includedfour examples from this ten CTMs: "the UCLA Autism Program by Lovaas and colleagues (Smith, Groen, \& Winn, 2000), the TEACCH program developed by Schopler and colleagues (Marcus, Schopler, \& Lord, 2000), LEAP model (Strain \& Hoyson, 2000 ) and the Denver model conceived by Rogers and colleagues (Rogers, Hall, Osaki, Reaven and Herbison, 2000)". (C. Wong \& al, 2014, p. 3)

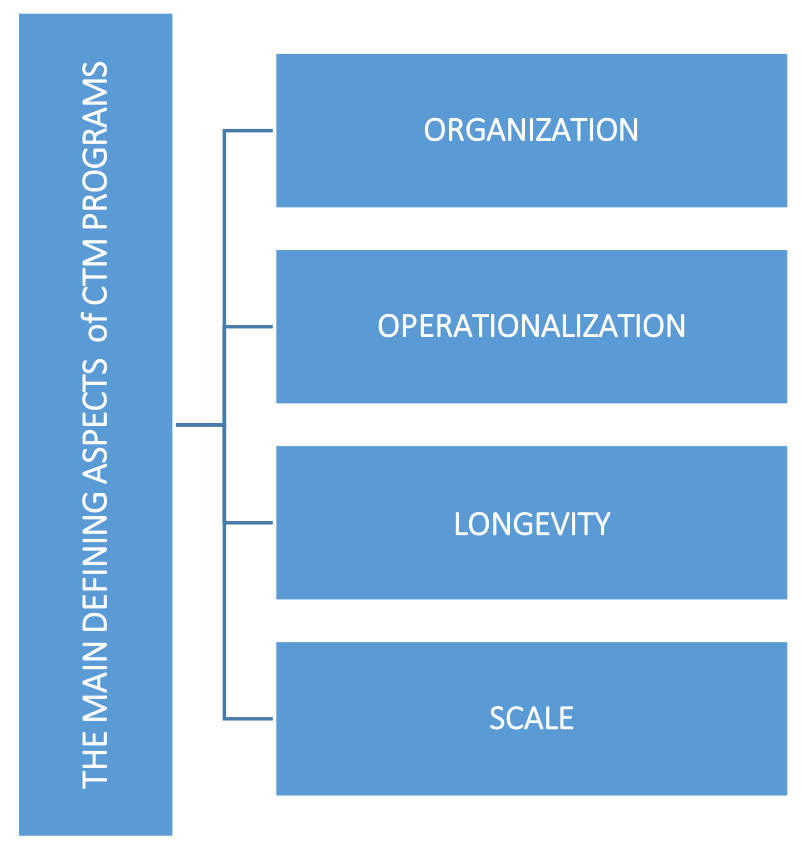

Figure 2. The main defining aspects of CTM programs

The main defining aspects of these programs are presented in Figure 2: "organization (around a conceptual framework), operationalization (a substantial number of hours per week), longevity (occurring over one or more years) and scale (multiple outcomes such as communication, behaviour, targeted social competence)" (Odom, Boyd, Hall, \& Hume, 2014, p. 3).

Original designs evolved and new CTMs were developed based on different theoretical and conceptual frameworks.

Although there is still a particular focus on operationalization, greater awareness of the need for accurate measurement of fidelity and implementation has emerged. 
Following an analysis realised by the National Academy, Odom et al. (2010) identified 30 CTM programs operating in the US. Replications or uses of the CTMs could increase in the future by more accurately measuring implementation and lessons learned from the wider science of implementation. Accompanying such increases is the continuing need to examine the effectiveness of the CTM by the supplier and assess the scalable implementation of CTMs by researchers other than suppliers. Such evidence will strengthen the argument for adoption of CTM through programs to be used in day-to-day practice, although adoption will also be influenced by community and socio-political contexts. (Odom et al., 2014)

Odom et al. (2010) appreciate that "more than half of the 30 models revised had no evidence of efficacy published in a peerreviewed journal."

Rogers \&Vismara (2008)"finding limited evidence of efficacy for all but the Lovaas model, with some limited support for Pivotal Response Treatment (PRT)"

\section{Review of evidence - based practice in ASD}

Webster, A; Cumming, J.; Rowland, S. (2017, p. 29) quoting Simpson (2005) says that "evidence-based practice involves using those interventions, treatments, or strategies that have been shown through scientifically-based research to lead consistently to specific outcomes for students with ASD"

Founded in the 1960s in England, EBP for students with ASD has its origin in evidencebased medical sciences. Later, this conceptual approach to evidence-based practices has also developed in the social sciences of the conceptual approach based on evidence in social sciences.

Since the 1990s, clear criteria have been established in the US to classify an intervention practice as effective or "possibly effective," depending on the precedent for quantification of the quantity and type of evidence needed to establish evidence-based practices (Chambless \& Hollon, 1998). The distinction between efficacy and efficacious psychological treatmenthas been achieved.

In this section, we will focus on how reviewing ASD research can make an objective picture of the importance of evidence in choosing intervention practices. 
In order to this objective, we will present the complex analysis realised by Wong et al. in The paper titled Evidence-Based Practices for Young, Young and Young Adults with Spectrum Autism (2014).

Table 1. Working Definitions for EBPs(Connie Wong, Samuel L. Odom, 2014)

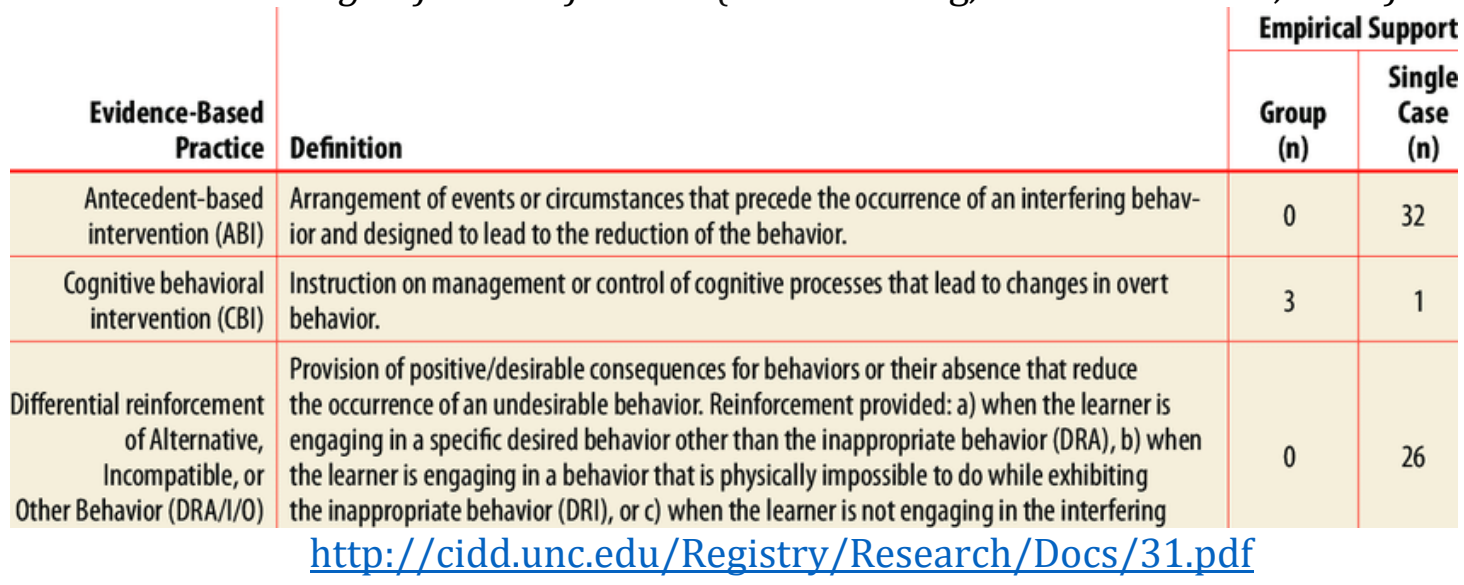

Inclusion criteria for "studies in the review articles were published in peer-reviewed, English language journals between 1990 and 2011 and tested the efficacy of focused intervention practices; using a conceptual framework followed by the Cochrane Collaborative - Participants, Interventions, Comparison, Outcomes, Study Design (PIC0)" (see the table below) (Wong et al., 2014, p. 9). The Table 2 content the type of diagnostic and intervention used in this research.

Table 2. Inclusion Criteria for Studies (Connie Wong, Samuel L. Odom, 2014)

\begin{tabular}{r|l}
$\begin{array}{r}\text { Population/ } \\
\text { Participants }\end{array}$ & $\begin{array}{l}\text { Individuals with ASD } \\
\text { between birth and 22 years of age }\end{array}$ \\
\hline Interventions: & $\begin{array}{l}\text { Behavioral, developmental, or educational in } \\
\text { nature and could be implemented in } \\
\text { typical educational intervention settings } \\
\text { (school, home, community) }\end{array}$ \\
\hline Comparison & $\begin{array}{l}\text { Interventions compared to no intervention or } \\
\text { alternate intervention conditions }\end{array}$ \\
\hline Outcomes & $\begin{array}{l}\text { Behavioral, developmental, or } \\
\text { academic outcomes }\end{array}$ \\
\hline Study Design & $\begin{array}{l}\text { Experimental group design, } \\
\text { quasi-experimental group design, or } \\
\text { single-case design }\end{array}$ \\
\multicolumn{2}{|c|}{ http://cidd.unc.edu/Registry/Research/Docs/31.pdf }
\end{tabular}


As regarding of the scanning of specialized articles and the underlying criteria are concerned, Table. 3 illustrates the keywords used to search in electronic databases.

\begin{tabular}{r|c} 
Category & $\begin{array}{c}\text { Table 3. Search Terms (Connie Wong, Samuel L. Odom, 2014) } \\
\text { Qualifying Terms }\end{array}$ \\
\hline Diagnostic & autism OR Asperger OR pervasive developmental disorder \\
\hline & AND \\
\hline Intervention & intervention OR treatment OR practice OR strategy OR therapy OR program OR procedure
\end{tabular}

(http://cidd.unc.edu/Registry/Research/Docs/31.pdf)

In the screening procedure conducted by Wong et al. (2014) were included a number of 1,090 articles, 213 utilizing a group design and 877 using quasi-experimental group design (SCD) methodology. The articles were identified by a group consists in one hundred fifty-nine reviewers. "All reviewers had a doctoral degree, master's degree, or were enrolled in a graduate education program at the time of the review. Most reviewers received their degrees in the area of special education or psychology and were faculty (current or retired), researchers, or graduate students. The majority of reviewers had professional experience in a classroom, clinic, or home setting and conducted research related to individuals with ASD. In addition, approximately one-third of the reviewers $(n=53)$ had Board Certified Behaviour Analyst (BCBA) or Board Certified Assistant Behaviour Analyst (BCaBA) certification."(Connie Wong, Samuel L. Odom, 2014, p. 14).

Most of the participants in the study were children with ages between 6-11 years, and preschool children (3-5 years). 
Table 4. Outcomes Identified in Studies(Connie Wong, Samuel L. Odom, 2014)

\begin{tabular}{l|c} 
Outcomes related to & $\begin{array}{c}\text { Studies } \\
\text { (n) }\end{array}$ \\
\hline $\begin{array}{l}\text { Social } \\
\text { Skills needed to interact with others }\end{array}$ & 165 \\
\hline $\begin{array}{l}\text { Communication } \\
\text { Ability to express wants, needs, choices, feelings, or ideas }\end{array}$ & 182 \\
\hline $\begin{array}{l}\text { Challenging/Interfering Behaviors } \\
\text { Decreasing or eliminating behaviors that interfere with the individual's } \\
\text { ability to learn }\end{array}$ & 158 \\
\hline $\begin{array}{l}\text { Joint Attention } \\
\text { Behaviors needed for sharing interests and/or experiences }\end{array}$ & 39 \\
\hline $\begin{array}{l}\text { Play } \\
\text { Use of toys or leisure materials }\end{array}$ & 77 \\
\hline $\begin{array}{l}\text { Cognitive } \\
\text { Performance on measures of intelligence, executive function, problem } \\
\text { solving, information processing, reasoning, theory of mind, memory, } \\
\text { creativity, or attention }\end{array}$ & 15 \\
\hline
\end{tabular}

(http://cidd.unc.edu/Registry/Research/Docs/31.pdf)

According to these analyses, „twenty-seven practices met the criteria for being evidence-based."(Wong, \&Odom, 2014, p. 19)

"The evidence-based practices consist of interventions that are fundamental applied behaviour analysis techniques (e.g., reinforcement, extinction, prompting), assessment and analytic techniques that are the basis for intervention (e.g., functional behaviour assessment, task analysis), and combinations of primarily behavioural practices used in a routine and systematic way that fit together as a replicable procedure (e.g., functional communication training, pivotal response training); the process through which an intervention is delivered defines some practices (e.g., parent-implemented interventions, technology-aided interventions)." (Wong, \&Odom, 2014, p. 19)

A centralized situation of the intervention practices is presented in Table 5. The authors of this Rapport (Wong at al.) found that 27 focused intervention practices meet the evidence-based criteria, including five new categories of EBP: cognitive behavioural interventions, exercises, modelling, scripting and structured gaming groups.

Also, the new technology-assisted training and intervention practice reflects an extension of the definition of technological interventions for ASD students, leading to 
computer-assisted training courses and speech / VOCA generating devices that are included in this classification.

Table 5. Evidence - based practices Raport 2014

\section{NPDC Evidence-Based Practices for Children, Youth, and Young Adults with Autism Spectrum Disorder: \\ EBP Report 2014}

- Antecedent-based interventions

- Cognitive-behavioral intervention

- Discrete Trial Teaching

- DRA/I/O

- Exercise

- Extinction

- Functional Behavioral Assessment

- Functional Communication Training (FCT)

- Joint attention interventions

- Modeling

- Naturalistic teaching strategies

- Parent implemented interventions

- Peer-mediated strategies

- Picture Exchange Communication System (PECS)
- Pivotal Response Training

- Prompting

- Reinforcement

- Response interruption/redirection

- Scripting

- Social narratives

- Self-management

- Social skills training

- Structured play group

- Task analysis

- Technology-aided instruction

- Time delay

- Video Modeling

- Visual Supports

Foundations in Autism Spectrum Disorders \& Evidence-Based Practices

\section{Conclusions}

The main purpose of this article was to analyse how the effectiveness and quality of educational and therapeutic practice in ASD are influenced by research in the field by identifying those interventions and effective, scientifically validated treatments for students with ASD.

Initially, we presented the current conceptualization of ASD, the review of scientific literature, analysis of research studies, identification and analysis of practices.

We intended to identify the link between educational practices and studies that provide empirical support for these practices.

Indeed, an educational and therapeutic practice is based on scientifically guided research if there is clear evidence that the program or practice is working. 


\section{References}

American Psychiatric Association (2013). Diagnostic and statistical manual of mental disorders (5th edition), Washington DC.

Cavanaugh, Carli M., Teachers Perceptions of Interventions for Children with Autism in a School Setting (2012).Counsellor Education Master's Theses. 122.

http://digitalcommons.brockport.edu/edc theses/122

Chambless, D. L.; Hollon, S. D. Defining Empirically Supported Therapies. In Journal of Consulting and Clinical Psychology. 66(1), 7-18.

Ennis-Cole, D. L. (2015). Technology for Learners with Autism Spectrum Disorders. Switzerland: Springer International Publishing.

Hume, K., et al. Assessing implementation of comprehensive treatment models foryoung childrenwith ASD: Reliability and validity of two measures. Research in Autism Spectrum Disorders, doi: 10.1016/j.rasd.2011.02.002.

Little, C. A., (editor) (2017).Supporting social inclusion for students with autism spectrum disorders: insights from research and practice. New York, NY: Routledge.

Odom. S. L.; Boyd, B., A.; Hall, L. J.; Hume, K. A. Comprehensive Treatment Models for Children and Youth with Autism Spectrum Disorders. In Volkmar, F. R.; Paul, R; Rogers, S. J.; Pelphrey, K. A. (2014). Handbook of Autism and Pervasive Developmental Disorders, Fourth Edition. John Wiley \& Sons.

Rogers S.J.; Vismara L. A. Evidence-based comprehensive treatments for early autism. In J Clin Child Adolesc Psychol. 37(1):8-38. doi: 10.1080/15374410701817808.

Tutunaru, R. Incluziunea şcolară şi incluziunea socială a copiilor cu cerinţe educaţionale speciale. Contribuţii ale cadrelor didactice itinerante, Revista de Asistenţă Socială, Nr.1/2018.

Wong, C.; Odom, S. L.; Hume, K. Cox A. W.; Fettig, A.;Kucharczyk, S., ... Schultz, T. R. (2014). Evidence-based practices for children, youth, and young adults with Autism Spectrum Disorder. Chapel Hill: The University of North Carolina, Frank Porter Graham Child Development Institute, Autism EvidenceBased Practice Review Group.

Webster, A; Cumming, J.; Rowland, S. (2017). Empowering Parents of Children with Autism Spectrum Disorder Critical Decision-making for Quality Outcomes. Springer Science+Business Media Singapore.

Comprehensive Treatment Models. http://www.researchautism.net/glossary/1528/comprehensive-treatmentmodelsaccesed in nov. 2018. 